\title{
Ensinar Ética é também ensinar a argumentar: análise de cinco falhas comuns de justificação ética
}

Cínthia R. Oliveira*
Marcelo J. Doro**

\begin{abstract}
Resumo
O ensino de filosofia no Ensino Fundamental e Médio constitui um desafio para o professor comprometido com o desenvolvimento da capacidade reflexiva e crítica dos alunos. Parte desse desafio é o ensino da Ética, que, com muita facilidade, pode virar doutrinação ou ficar numa mera discussão das opiniões, caso o professor não esteja atento aos argumentos dos estudantes para problematizá-los e aprofundá-los adequadamente. As aulas de Ética, para que desenvolvam a capacidade de fazer juízos éticos sensatos, devem se fundamentar no uso de bons argumentos; para tanto, cabe ao professor saber identificar as falácias, comumente usadas pelos estudantes na justificação dos comportamentos que acham corretos, e mostrar suas fraquezas. Dessa forma, o presente artigo pretende analisar cinco falhas frequentes de justificação ética, a saber: petição de princípio, apelo à maioria ou apelo ao povo, dois erros fazem um acerto, apelo à tradição e falácia naturalista. A discussão dessas falácias, frequentemente usadas para justificar comportamentos éticos, pretende auxiliar professores e futuros professores de Filosofia a problematizar as opiniões e pretensas justificações dos estudantes nas aulas de Ética, para que de fato as aulas de Filosofia como um todo desenvolvam o raciocínio crítico e a criatividade de seus participantes.
\end{abstract}

Palavras-chave: Ensino de filosofia; Ética; Falácias.

\section{Teaching Ethics is also teaching argumentation: analysis of five common failures in ethical justifications}

\begin{abstract}
Philosophy teaching in primary and secondary education is a challenge for the teacher committed to the development of the students' reflective and critical skills. Part of this challenge is the teaching of ethics, that can very easily become indoctrination or remaining in a mere discussion of opinions, in case the teacher is not aware of the arguments of the students to discuss them and deepen them properly. The Ethics classes, as to develop the

\footnotetext{
* Cínthia Roso Oliveira é doutoranda em Filosofia pela Universidade do Vale do Rio dos Sinos. E-mail: cinthiarsm@gmail.com.

${ }^{* *}$ Marcelo José Doro é doutorando em Educação pela Universidade de Passo Fundo e participa do Grupo de Pesquisa Núcleo de Pesquisas em Filosofia e Educação (NUPEFE UPF). E-mail: marcelodoro@upf.br
} 
ability to make reasonable ethical judgments should be based on the use of good arguments; for such, the teacher needs to be able to identify the fallacies commonly used by students on justifying behaviors that they consider right, and show them the weaknesses of those justifications. Thus, this article aims to analyze five common failures of ethical justification, namely: circular reasoning, appeal to the bandwagon or appeal to the people, two wrongs make a right, appeal to tradition and naturalistic fallacy. The discussion of these fallacies, often used to justify ethical behavior, aims to help teachers and future teachers of philosophy to question the students' views and alleged justifications in ethics classes, so that the philosophy classes as a whole in fact develop critical thinking and the creativity of its participants.

Keywords: Philosophy teaching; Ethics; Fallacies.

\section{Introdução}

A Ética constitui um dos principais eixos temáticos do ensino de filosofia, do qual se espera uma importante contribuição para a formação de sujeitos socialmente comprometidos e responsáveis. Mas como a Ética deve ser trabalhada na escola para que isso de fato aconteça? Como deve acontecer, em suma, o ensino da Ética?

Estas não são questões simples e não existem respostas simples para elas. Sem poder desdobrar, aqui, as muitas possibilidades de abordagem para estas questões, assume-se como ponto de partida a perspectiva de que ensinar Ética não é simplesmente repassar conteúdos, apresentando suas grandes linhas teóricas e principais representantes, muito menos promover a doutrinação dos estudantes nos valores e normas da moralidade dominante; pelo contrário, parte-se do pressuposto de que ensinar Ética é qualificar a capacidade de fazer juízos éticos sensatos. Implícito nisso está também a concepção de que em Ética deve-se estar sempre em condições de justificar com boas razões tanto o próprio comportamento quanto as avaliações de comportamentos alheios.

Diante dessa perspectiva, busca-se, pela análise de cinco falhas frequentes de justificação ética, reforçar a importância da boa argumentação para o ensino desta área da Filosofia. Pois, como já defendiam Lipman, Sharp e Oscanyan (1994), se o ensino de filosofia deve desenvolver a criatividade, a capacidade de raciocinar, promover o crescimento pessoal e interpessoal e a compreensão ética, 
isso só é possível se os estudantes pensarem por si mesmos e em conjunto (na comunidade de investigação), exercitando seu raciocínio e percebendo, através da ajuda do professor, quando não estiverem raciocinando bem.

\section{Cinco falhas de argumentação comuns em discussões éticas}

As falhas argumentativas apresentadas abaixo são falácias já catalogadas', que foram selecionadas em função da alta frequência com que costumam ser empregadas nos discursos cotidianos e, sobretudo, nas discussões éticas oportunizadas em sala de aula.

a) Petição de princípio. Trata-se de um círculo afirmativo em que a justificação oferecida para uma posição pressupõe a aceitação prévia dessa posição. Argumentos desse tipo não são inválidos em sua estrutura lógica, uma vez que a verdade das premissas garante a verdade da conclusão; o problema reside no fato de o argumento não apresentar evidência alguma para a sustentação da conclusão pretendida, dado que a as premissas repetem ou pressupõem a conclusão. Em suma, a petição de princípio é uma mera repetição de uma afirmação qualquer camuflada em estrutura argumentativa. Numa discussão ética, isso acontece, por exemplo, quando alguém alega que um comportamento é errado, porque não deveria ser praticado. A petição de princípio, neste caso, tornase ainda mais evidente ao se cobrar o esclarecimento sobre por que tal comportamento não deveria ser praticado. A resposta costuma ser: não deve ser praticado, obviamente, porque é errado! É fácil notar que, com esse tipo de justificação, não se acrescenta nada à avaliação de uma situação ética, tampouco se avança na capacidade de dar boas razões para comportamentos.

b) Apelo à maioria ou apelo ao povo. Esta é clássica. Talvez constitua a forma mais frequente de (pseudo) justificação ética. Basicamente, consiste na

\footnotetext{
1 As principais referências conceituais usadas para a caracterização das falácias aqui apresentadas são Stephen's Guide to the Logical Fallacies, de Stephen Downes, e Forty Two Fallacies, de Michael Labossiere. Os exemplos foram coletados da própria prática no ensino da ética.
} 
pretensão de validar um comportamento em função de sua ampla aceitação no grupo social; ou, inversamente, em negar a validade de um comportamento em função de sua ampla rejeição no grupo social'2. Um exemplo: uma vez que, atualmente, a infidelidade tornou-se uma prática comum, já não convém condená-la. Outro exemplo: todo mundo já pirateou alguma coisa via internet, então não há nada de mal nisso. Ambos os exemplos partem de uma confusão básica entre vigência e validade das normas morais. A validade de uma norma precisa ser considerada a partir de sua adequação aos princípios éticos e não em função da adesão das pessoas a ela. Normas de valor duvidoso e, por vezes, claramente indignas, já foram socialmente toleradas e praticadas - a aceitação da escravidão em tempos passados e a tolerância ao "jeitinho brasileiro" exemplificam bem esta condição. As questões éticas não podem ser decididas por um princípio democrático, na suposição de que, se a maioria assim acha, então assim é. Muitas pessoas, ou mesmo uma comunidade inteira, podem compartilhar uma prática preconceituosa, sem que isso implique a conclusão de que tal prática é aceitável do ponto de vista de uma ética racional ${ }^{3}$.

c) Dois erros fazem um acerto. Esta aparece com frequência em abordagens de temas como pena de morte e atos de justiçamento popular (linchamento). A ideia é que, se alguém comete um crime, especialmente um crime hediondo, o

\footnotetext{
2 Há uma ambiguidade nessa aceitação e rejeição, mas basicamente, quem pratica essa falácia: ou aceita que algo é certo porque a maioria das pessoas "acreditam" que algo seja certo, ou porque a maioria das pessoas "agem" de acordo com essa prática. E assim teríamos diferentes exemplos referentes a essa falácia. Quanto ao "acreditar": a) Porque a maioria das pessoas acredita em Deus, então ele deve existir; b) Porque a maioria das pessoas acha que é errado abortar, então é errado. Quanto ao "praticar": a) Porque a maioria das pessoas mente, então é certo mentir; b) Porque a maioria das pessoas repudia comportamentos homossexuais em público, então é certo repudiar esse tipo de comportamento. É necessário mostrar essa ambiguidade quanto ao "aceitar" podendo significar "acreditar" ou "praticar", porque muitas pessoas traem, mesmo que não achem certo trair, muito menos aceitariam ser traídas. Então, nem sempre as pessoas que agem de uma forma, conscientemente acham que essa forma é a correta. Mas quem pratica a falácia de apelo à maioria desconsidera isso, usando como the convier a aparente justificação e, consequentemente, cometendo um erro de raciocínio.

3 Essa é uma crítica endereçada ao Utilitarismo de Preferências, de Stuart Mill, segundo o qual um comportamento é bom se ele resultar na satisfação dos nossos desejos. Mas se uma maioria desejar algo que é intolerável, por exemplo, a maioria dos nazistas desejava a morte dos judeus, será bom matar os judeus, porque esse é o desejo predominante?
} 
correto é que receba uma punição exemplar, tão ou mais brutal que a ação cometida. A fragilidade desta lógica do "olho por olho, dente por dente" é a incoerência de punir um erro com outro erro. No discurso do senso comum, em que o linchamento é prática muitas vezes tolerável, por exemplo, sustenta-se a máxima de que "bandido bom é bandido morto", sem considerar que quem participa de linchamento também se torna bandido e merecedor da mesma punição. No mais, não faz sentido imaginar que, dada a ocorrência de um erro, o acréscimo de outro é a melhor alternativa. Na verdade, quanto pior, pior! Dois erros não fazem um acerto. E, contudo, este é um raciocínio bastante difundido, que aparece até em ditados populares: "ladrão que rouba ladrão tem cem anos de perdão".

d) Apelo à tradição. Está também é clássica. E muito frequente. Consiste, grosso modo, na suposição de que, se um comportamento é praticado há muito tempo, então ele se torna válido. Ou, diferentemente, se um comportamento tem um histórico de rejeição, então ele não é válido. Aqui, se alguém cobra uma justificação para um comportamento, a resposta é direta: sabemos que tal comportamento é correto, porque sempre foi assim. Ou: sabemos que isso é errado, porque desde sempre tem sido repudiado. Nessa linha são apresentados argumentos em defesa da continuidade da utilização de animais em práticas esportivas (caça, touradas etc.) e em experimentos científicos: há muito tempo o ser humano vem criando animais para esse fim, trata-se, portanto, de uma prática historicamente legitimada. Argumentos desse tipo também são formulados em defesa de práticas preconceituosas e exclusivistas: esta é uma profissão tradicionalmente ocupada por mulheres/homens, do que se conclui que não é apropriado para o outro sexo. A falha de argumentos assim deveria ser óbvia: a antiguidade de uma prática não quer dizer nada sobre sua validade, afinal, nada impede que um comportamento discriminatório e injusto seja integrado ao costume de um grupo e passado adiante como se fosse natural. Novamente, aqui, faz-se necessário avaliar a validade de um comportamento em relação aos princípios éticos, ou seja, trata-se de poder justificá-lo a partir de parâmetros racionais e não em função de seu histórico. E, vale sublinhar, a antiguidade não é um parâmetro racional de avaliação, como várias observações históricas em outras áreas podem 
facilmente mostrar: por muito tempo, por exemplo, as pessoas acreditaram que a Terra era plana, mas apesar da antiguidade da crença ela não era verdadeira; também por muito tempo a sangria foi usada como tratamento na medicina, mas apesar de tradicional foi abandonada em função de sua irrelevância.

e) Falácia naturalista. Grosso modo, alguém comete uma falácia naturalista sempre que tenta apoiar uma conclusão sobre comportamentos em noções de "bom" ou de "correto" que remetem a algum sentido natural desses termos. Dito de outro modo, comete-se uma falácia naturalista quando se transferem as noções de bom ou de ruim do plano natural para o plano ético, confundindo-se assim o ser com o dever ser. Esta falácia foi amplamente analisada por George Moore, no livro Principia Ethica (1999)4 . Um caso particular e muito comum de falácia naturalista é o apelo à natureza, que consiste em rotular como bom tudo o que é natural e como mau tudo o que é artificial. Claramente, trata-se de uma simplificação grotesca que, dentre outras coisas, desconsidera a imensa quantidade de produtos nocivos que existem naturalmente. Não obstante, por todos os lados surgem e são propagados argumentos desse tipo. Por exemplo, há quem defenda a desigualdade social e mesmo a exploração econômica de uma classe em relação à outra alegando que a competição e a sobreposição dos mais aptos é uma regra intrínseca à evolução da vida no planeta. Sim, isso é verdade, mas não significa que essa mesma lei natural deva regrar também a relação moral das pessoas. Outro exemplo comum: comer carne é um comportamento natural do ser humano e de muitas outras espécies também, logo, não faz sentido considerar essa prática antiética. O problema aqui é o mesmo: considera-se que, apenas porque um comportamento tem bases naturais, ele deve ser considerado bom. Novamente, é

\footnotetext{
${ }^{4}$ Hume (2000) também identificou o problema de derivar do "ser" um "dever ser", mas diferentemente de Moore, ele considera que qualquer derivação de "dever ser" a partir de elementos fatuais é errado, não considerando simplesmente elementos naturais, mas também culturais. Assim, o seguinte argumento também é considerado questionável diante da falácia naturalista, pois uma das premissas baseia-se numa questão fatual: $O$ aborto não deve ser proibido, pois ter filhos ou não, é uma questão de escolha pessoal e nenhuma questão de estrita escolha pessoal deve ser proibida. Ou ainda: É certo preferir contratar homens altos e bonitos para trabalhar com vendas, ao invés de mulheres, baixinhas e feitas, porque se sabe que as pessoas confiam mais em homens e que são altos e bonitos.
} 
preciso notar que essa não é uma conclusão necessária: pois existem práticas naturais que não são boas, como a agressividade, por exemplo.

Essa pequena amostra de argumentos ruins bastante comuns em discussões éticas deve ser suficiente para mostrar que o ensino da ética, para poder de fato preparar os estudantes para avaliações e juízos mais qualificados nesse campo, deve ter como aliada o estudo dos processos argumentativos. Do contrário, correse o risco de manter a problematização das questões éticas na superficialidade, sem garantir sequer a necessária desqualificação das posturas flagrantemente inconsistentes partilhadas pelo senso comum moral.

Mas como garantir que a discussão em sala de aula seja de fato filosófica e não vire uma mera expressão de opiniões descuidadas? Para Lipman, Sharp e Oscanyam (1994, p. 143-176), é papel do professor garantir que os alunos pensem adequadamente. Para isso, ele deve saber orientar o discurso filosófico de modo a explicitar as convergências de ideias ou as divergências, pedir definições, explicações, razões, entre outras, além de também, indicar falácias.

Não é necessário que o professor pare o conteúdo discutido para esclarecer - que são falácias e denominar a falácia utilizada pelo aluno. Mas a própria problematização das falas dos alunos pela turma e/ou professor pode levar a perceber a fraqueza de um argumento, sem que necessariamente se conheça os nomes dados às falácias. Isso caracterizaria bem a reflexão que deve ser feita por uma "comunidade de investigação". Portanto, é importante que o professor tenha consciência dos vários tipos de raciocínios incorretos, para perceber quando é necessário problematizar a fala de algum aluno que está pensando de forma falha.

No entanto, é interessante que no seu Plano de Curso, o professor planeje trabalhar conteúdos da Lógica, dentre eles os diversos tipos de Falácias, antes mesmo de outros conteúdos, pois isso facilitaria, depois, quando fosse necessário apenas relembrar o erro de raciocínio com a turma.

\section{Conclusão}


A tese defendida aqui é que, se o ensino de Ética deve preparar os estudantes para avaliar e decidir de forma sensata, isso pressupõe, em algum momento, a qualificação da capacidade argumentativa. Identificar, formular e avaliar argumentos é um dos pressupostos básicos daquilo que se chama de competência ética. Se não é possível, em Ética, alcançar posições absolutas, pelo menos é possível, argumentativamente, pela eliminação de avaliações parciais, incoerentes e infundadas, avançar em direção a respostas cada vez mais seguras.

E isso caracteriza bem uma boa aula de filosofia, que embora não se chegue a uma resposta final sobre um problema, uma discussão filosófica marca um progresso seja no esclarecimento de possíveis respostas para um problema, na melhor compreensão sobre um tema, na formulação de um problema, ou no esclarecimento dos problemas de raciocínio (LIPMAN; SHARP; OSCANYAN, 1994, p. 154-157).

Embora alguns desses progressos sejam mais modestos que outros, eles não são menos importantes, ao contrário, são imprescindíveis para que os mais complexos sejam alcançados na sequência. E perceber as falhas de raciocínio durante uma discussão filosófica é imprescindível para que ela chegue a um estado mais aprofundado de reflexão.

Sem a preparação adequada para o trato argumentativo, o ensino da Ética, pretendido como um espaço coletivo de reflexão e qualificação da capacidade de julgar, pode ficar irremediavelmente preso em aporias e falácias. E não é isso que se espera do Ensino de Filosofia!

\section{Referências Bibliográficas}

BRITO, Adriano N. de. Falácia Naturalista e Naturalismo Moral: do é ao deve mediante o quero. Kriterion, Belo Horizonte, v. 51, n. 121, p. 215-226, jun. 2010. Disponível em: <http://www.scielo.br/pdf/kr/v51n121/11.pdf>. Acesso em: 5 nov. 2014.

COPI, Irving. Introdução à Lógica. São Paulo: Mestre Jou, 1981.

DOWNES, Stephen. Stephen's Guide to the Logical Fallacies. Canada, 1995-2001. Disponível em: <http://www.onegoodmove.org/fallacy/welcome.htm>. Acesso em: 12 fev. 2014. 
FISHER, Alec. A Lógica dos Verdadeiros Argumentos. São Paulo: Novo Conceito, 2008.

HUME, David. Tratado da Natureza Humana. São Paulo: Unesp, 2000.

LABOSSIERE, Michael C. Forty Two Fallacies. Disponível em:

<http://aphilosopher.files.wordpress.com/2010/09/42-fallacies.pdf>. Acesso em: 13 fev. 2014.

LIPMAN, Matthew. A comunidade de investigação e o raciocínio crítico. São Paulo: Centro Brasileiro de Filosofia para Crianças, 1995.

LIPMAN, Matthew; SHARP, Ann M.; OSCANYAN, Frederick S. A filosofia na sala de aula. São Paulo: Nova Alexandria, 1994.

MOORE, George E. Principia ethica. Lisboa: Fundação Calouste Gulbenkian, 1999.

NOLT, John; ROHATYN, Dennis. Lógica. São Paulo: McGraw-Hill, 1991.

WESTON, Anthony. A Arte de Argumentar. Lisboa: Gradiva, 1996. 